\title{
Thermal Lesion of Renal Tumour as a Function of Catheter Material Property
}

\author{
Olumide A. Towoju and Moses O. Petinrin
}

\begin{abstract}
The extent of lesion achieved during microwave ablation is dependent on some factors which include the time period of application, its intensity, antenna geometry, and relative permittivity of the tissue. Several studies have been conducted on microwave ablation for the treatment of tumours and have focused on different antenna geometries, its intensity, and time of application. This work seeks to find a correlation between the relative permittivity of the catheter and the temperature distribution which determines necrosis of the tissue by using Tefzel ETFE, Teflon FEP, PFA Teflon type A, PFA Teflon type B, Teflon AF, and PTFE Teflon type $B$ while modelling using COMSOL Multiphysics. The extent of the thermal lesion was observed to be dependent on the relative permittivity of the catheter material, with Tefzel ETFE giving the best performance and Teflon AF providing the least.
\end{abstract}

Index Terms-Microwave Ablation; Necrosis; Relative Permittivity.

\section{INTRODUCTION}

Microwave ablation and radiofrequency ablation, the two most commonly used heat ablation which are minimally invasive procedure are been increasingly used for the treatment of tumours and cancerous cells based on the principles of hyperthermia using image guidance systems for antenna insertion. Necrosis is induced by hyperthermia as a result of protein coagulation and denaturation. Normothermia, the normal human body temperature falls within the range of $36.5-37.5^{\circ} \mathrm{C}$ [1], and body temperatures a few degree Celsius above this can be lethal. The inability of tumours to cause an increased blood flow in response to heat application as does a normal cell makes them act as heat sinks and thus more vulnerable to damage is exploited for its treatment [2].

Different pieces of literatures have given different values of temperature as lethal to human cells; however, there seems to be a pointer to a value above $42^{\circ} \mathrm{C}$ [2]-[5].

The application of heat for treatment especially for the case of the dreaded cancer cells and for pain relief although of recent gaining relevance have been in existence for a very long time and this can be attested to from the quotes of Hippocrates "Those who cannot be cured by medicine can be cured by surgery. Those who cannot be cured by surgery can be cured by fire (heat). Those who cannot be cured by fire, they are indeed incurable" Hippocrates $(479-377$ B. C.)

Published on September 18, 2018

O. A. Towoju (Corresponding Author) is with Adeleke University, Ede, Nigeria (e-mail: olumidetowo@yahoo.com).

M. O. Petinrin is with University of Ibadan, Nigeria (e-mail layopet01@yahoo.com).
As good and effective hyperthermia is in the treatment of tumours, care must be taking in is administration as studies have shown that mild thermo-tolerance can set in if cells are heated to a temperature of $40^{\circ} \mathrm{C}$ for about three hours [2]. This could, however, also be put to an advantage by making the surrounding cells of a tumour site to develop thermotolerance, and are made to survive the subsequent application of lethal temperatures to the tumour site.

Microwave ablation is usually favoured over radiofrequency ablation as it is believed to be less dependent on electrical conductivities of tissues and provides consistent higher intra-tumour temperatures making it more effective for the treatment of larger sized tumours as a result of larger ablation zones [3],[6]-[12].

Microwave ablation involves the use of electromagnetic radiations having a wavelength range of between one millimetre and one meter delivered through special purpose antennas and are capable of causing rapid temperature increase adequate enough to achieve necrosis [3],[13]-[16]. The theory of the concept of microwave ablation is available in many pieces of literatures, and basically this entails the use of electromagnetic field to cause water molecules in tissues to oscillate and the subsequent absorption of the electromagnetic energy and its conversion to heat [3],[10],[14], [17]-[18]. It has evolved as a modality for the treatment of large soft tissues in short time periods.

Renal microwave ablation using image guidance systems are offering a viable alternative to partial nephrectomy just like other microwave application modes, especially where small tumours are involved, [10] as it allows for faster recovery period, offers a lifeline to patients who are not amenable to surgery due to one or more reasons, and at a reduced cost [3],[11],[14],[19]-[23].

The extent of lesion achieved during microwave ablation is a function of its propagation, and is determined by the time of application, the intensity, antenna geometry, and the relative permittivity of the tissue [3],[15],[17],[23]-[25] and are now the standard option for tumour size less than $7 \mathrm{~cm}$ [26]. However, with larger sizes of tumours, multiple antennas can be employed to achieve greater ablation zone [27]-[28].

Different antenna geometries have been proposed and studied by many scholars, they are thin co-axial based and have been categorised basically as monopole, dipole, and slot [9],[13],[15],[23],[29]-[30]. Undertaking studies on monopole, single slot, double slot and sleeved antennas, it was observed that the sleeved antenna type showed the best performance in terms of ablation sphere shape index and temperature distribution [13]. The antenna geometry is always done in a way as to fulfil some basic requirements of being minimally invasive and highly efficient [31]. 
The typical frequencies used for microwave ablation as adopted by the Federal Communications Commission are $915 \mathrm{MHz}$ and the $2.45 \mathrm{GHz}$ [3],[12]-[15],[17],[22][23],[28], these are so chosen to avoid interference with other waves emitting and absorbing devices/equipment.

The efficacy of microwave ablation antennas is determined by the specific absorption ratio (SAR) which is the electromagnetic power deposited per unit mass of the tissue [9], and the ablation zone ideally is expected to be spherical [3],[31]. The catheter material and its dimensions also contribute to the antenna performance.

To ensure better prediction and production of spherical ablation zones, a new technology "the Thermosphere" have been developed and it relies on three modes of energy control: wavelength, thermal and field controls [18],[25].

Studies carried out on microwave ablation heating pattern suggest that there are changes in SAR at elevated temperatures (above $100^{\circ} \mathrm{C}$ ) as it was experimentally observed, however, this was not the case for simulation studies mainly due to the fact of the non-proper capturing of the temperature dependence nature of the dielectric properties of tissues at elevated temperatures [12].

This study is focussed on the extent of thermal lessen achieved with the use of different materials as the catheter in microwave ablation.

\section{MATERIALS AND METHODS}

The numerical modelling approach developed for cancer microwave therapy by COMSOL [32] was adapted for the coaxial slot antenna geometry.

The simulation of the kidney ablation zone achieved by the antenna was carried out using the radiofrequency and heat transfer modules in COMSOL Multiphysics.

The transverse electromagnetic field characterise the coaxial cable electromagnetic field propagation and are governed by the following equations in a two-dimensional axially symmetric cylindrical coordinates;

$$
\begin{aligned}
& E(r)=e_{r} \frac{C}{r} e^{j(\omega t-k z)} \\
& H(r)=e_{\varphi} \frac{C}{Z} e^{j(\omega t-k z)} \\
& \text { And } C=\sqrt{\frac{P_{a} Z}{e_{z} \pi I n\left(\frac{r_{o u t}}{r_{\text {in }}}\right)}}
\end{aligned}
$$

where $\omega$ is the angular frequency, $r_{\text {in }}$ and $r_{\text {out }}$ are the inner and outer radii of the dielectric, $\mathrm{Z}$ is the wave impedance in the dielectric of the coaxial cable, $P_{a}$ is the input power, $r, \varphi$, and $\mathrm{z}$ are the cylindrical coordinates centred on the axis of the coaxial cable.

The propagation constant " $k$ " also referred to as the wave number $=\frac{\omega}{V}$, and noting that $\omega=2 \pi f$, and $V=f \lambda$, hence " $k$ " can be expressed in terms of the medium wavelength as;

$$
k=\frac{2 \pi}{\lambda}
$$

Since the magnetic field is purely azimuthally in direction and the electric field has a finite axial component, the antenna can be modelled using the axial symmetric transverse magnetic formulation with the source modelled using a low-reflecting boundary condition.

$$
n * \sqrt{\varepsilon E}-\sqrt{\mu H_{\varphi}}=-2 \sqrt{\mu H_{\varphi 0}}
$$

The time-dependent heat transfer equation is governed by the bio-heat equation;

$\rho C_{p} \frac{\partial T}{\partial t}+\nabla \cdot(-k \nabla T)=\rho_{b d} C_{b d} \omega_{b d}\left(T_{b d}-T\right)+Q_{m}+Q_{e}$

where $Q_{e}$ is the external heat source, $Q_{m}$ is the heat from metabolism, $T_{b d}$ is the blood temperature, $\omega_{b d}$ is the rate of blood perfusion, $C_{b d}$ is specific heat capacity of blood, $\rho_{b d}$ is the density of blood, and $k$ is the thermal conductivity of kidney.

The heat from metabolism can be neglected, making (6) to become;

$$
\rho C_{p} \frac{\partial T}{\partial t}+\nabla \cdot(-k \nabla T)=\rho_{b d} C_{b d} \omega_{b d}\left(T_{b d}-T\right)+Q_{e}
$$

The tissue damage integral during the process was computed using the Arrhenius equation as expressed in (8) and the fraction of necrotic tissue is expressed in (9) ;

$$
\begin{aligned}
& \frac{d \alpha}{d t}=F \exp \left(-\frac{d E}{R T}\right) \\
& \theta_{d}=1-\exp (-\alpha)
\end{aligned}
$$

where $\alpha$ is the degree of tissue injury, $F$ is the frequency factor, $d E$ is the irreversible damage activation energy, and $\theta_{d}$ is the fraction of necrotic tissue.

The antenna specific absorption rate (SAR) was computed using;

$$
S A R=\frac{\sigma}{2 \rho}|E|^{2}
$$

$\sigma$ is the tissue conductivity and $\rho$ is the tissue density.

The impact of the relative permittivity of the antenna dielectric material on its performance was studied by using available alternative materials to polytetraflouroethylene (PTFE). The relative permittivity of the materials chosen is stable for a temperature range of $(-55-125){ }^{\circ} \mathrm{C}$, and hence the simulation was carried out such that the maximum temperature attained was less than $125^{\circ} \mathrm{C}$. The properties of the materials used in the simulation are given in Table I. Antenna frequency of $2.45 \mathrm{GHz}$ was used and the blood temperature was taken to be $37^{\circ} \mathrm{C}$. The other parameters used in the simulation are as shown in Table II.

The simulation does not model the interior of the metallic conductors and the tangential component of the electric field is set to zero to model the metallic parts.

\section{TABLE I: MATERIAL PROPERTIES}

\begin{tabular}{lll}
\hline \hline Materials & $\begin{array}{l}\text { Relative } \\
\text { permittivity }\end{array}$ & Conductivity $(\mathrm{S} / \mathrm{m})$ \\
\hline Kidney & 52.7 & 2.43 \\
Inner dielectric & 2.03 & \\
\hline \hline
\end{tabular}




\begin{tabular}{ll}
\hline \hline Catheter & \\
Tefzel ETFE & 2.311 \\
Teflon FEP & 2.067 \\
PFA Teflon type A & 2.049 \\
PFA Teflon type B & 2.024 \\
Teflon AF & 1.871 \\
PTFE Teflon type B & 2.037 \\
\hline \hline
\end{tabular}

\begin{tabular}{ll}
\multicolumn{2}{c}{ TABLE II: BLOOD PROPERTIES } \\
\hline \hline Property & Value \\
\hline Density & $1045\left(\mathrm{~kg} / \mathrm{m}^{3}\right)$ \\
Specific heat & $3639(\mathrm{~J} /(\mathrm{kg} . \mathrm{K}))$ \\
Perfusion rate & $0.0036(1 / \mathrm{s})$ \\
Temperature & $37\left({ }^{\circ} \mathrm{C}\right)$ \\
\hline \hline
\end{tabular}

The mesh parameters used for the simulation is as shown in Table III.

\begin{tabular}{ll}
\multicolumn{2}{c}{ TABLE III: MESH PARAMETERS } \\
\hline \hline Maximum element size & $1.5 \mathrm{e}-4 \mathrm{~m}$ \\
Minimum element size & $2.4 \mathrm{e}-5 \mathrm{~m}$ \\
Maximum element growth rate & 1.3 \\
Curvature factor & 0.3 \\
\hline \hline
\end{tabular}

\section{RESUlTS}

Fig. 1, 2, 3, and 4 are the output plots for the temperature distribution, necrotic tissue fraction in surface plot, necrotic tissue fraction at four points; $4 \mathrm{~mm}, 6 \mathrm{~mm}, 8 \mathrm{~mm}$ and $10 \mathrm{~mm}$, and the specific absorption rate at point $2 \mathrm{~mm}$ from the antenna axis respectively.

The Tefzel ETFE with the highest relative permittivity value was observed to have the highest peak temperature and as depicted in Fig. 1, its temperature distribution as shown by the oval shape for the lethal value is the largest. Teflon AF with the least value of relative permittivity showed the least giving an indication of its dependency on the relative permittivity.

The necrotic tissue fraction achieved during the process was also observed to be best with the use of Tefzel ETFE as is evidenced in Fig. 2 and Fig. 3. The necrotic fraction with the use of Tefzel ETFE was ' 1 ' at a radial distance $8 \mathrm{~mm}$ from the conductor at a time of twenty-five (25) minutes and 0.6 at a radial distance of $10 \mathrm{~mm}$ at time ' $\mathrm{t}$ ' = thirty (30) minutes which from Fig. 3 is the best recorded for any of the catheter materials used in this study. Teflon AF showed to be the least effective of all the catheter materials used.

The specific absorption ratio (SAR) along a line parallel to the antenna and at a distance $2 \mathrm{~mm}$ from the antenna axis was also observed to be highest for Tefzel ETFE and least for Teflon AF as evidenced in Fig. 4.

The major objective of microwave ablation therapy is to destroy cancerous cells and tumours, and the extent of its destruction is connoted by the necrotic fraction which is a function of the electromagnetic power deposited per unit mass of tissue.

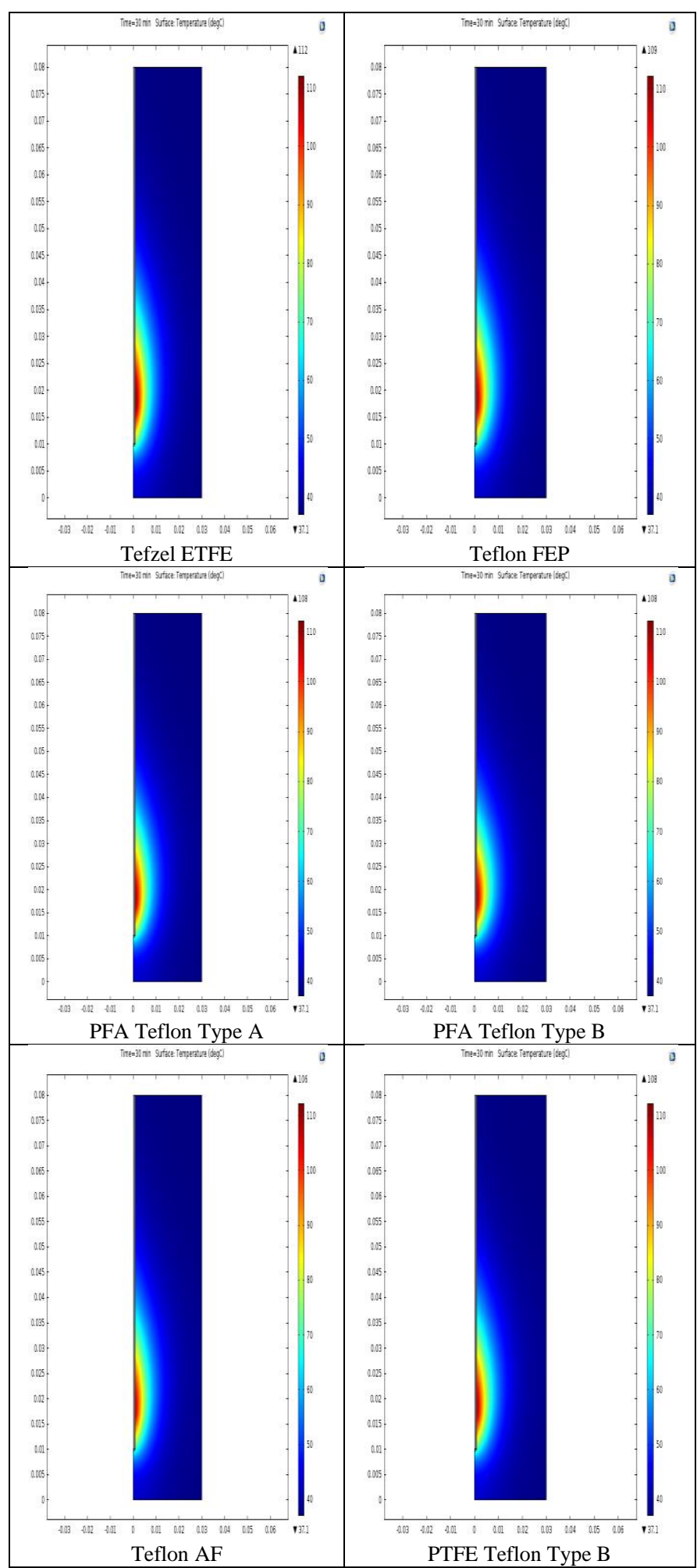

Fig. 1. Temperature distribution in Kidney tissue 

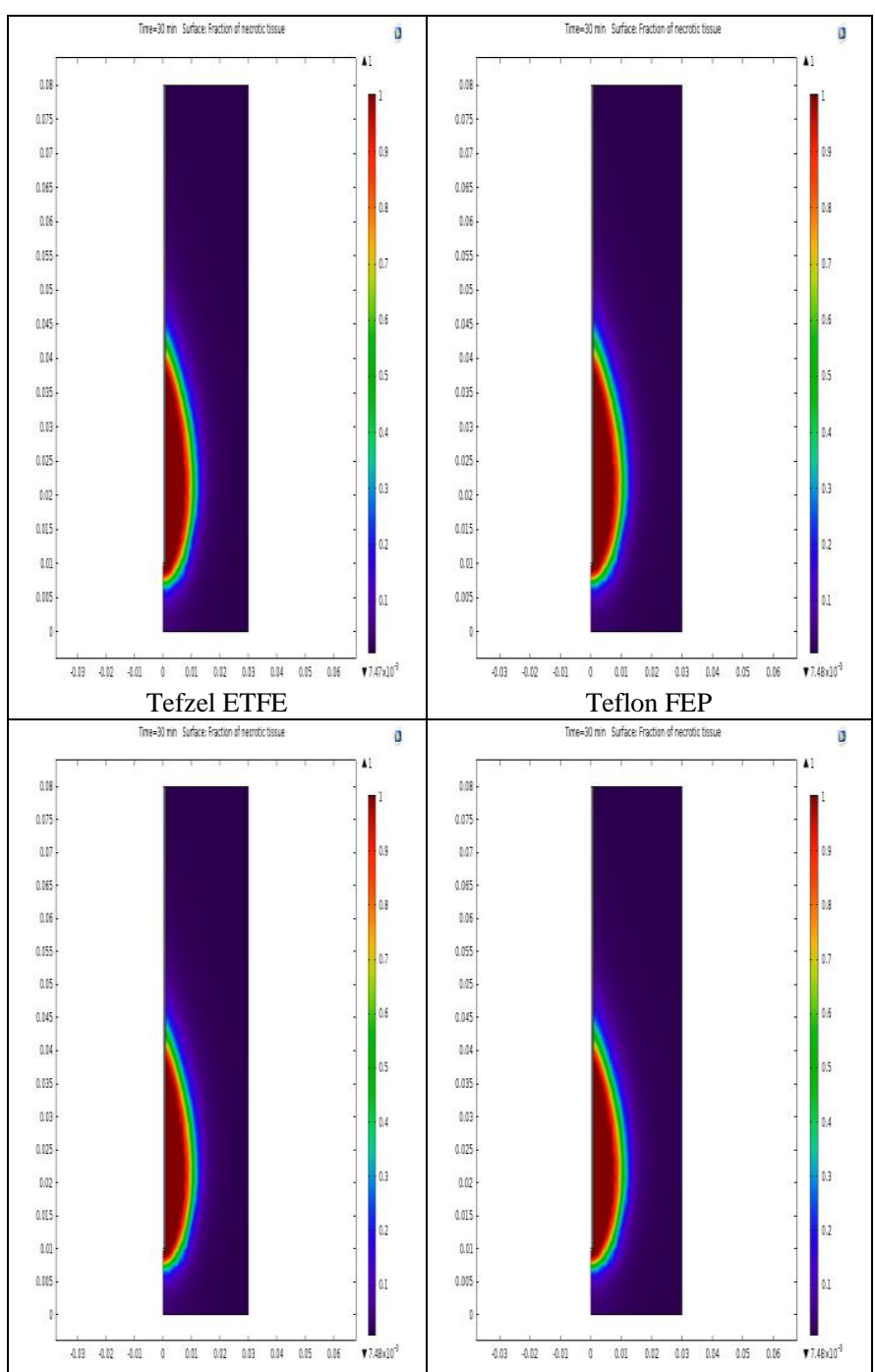

PFA Teflon Type A

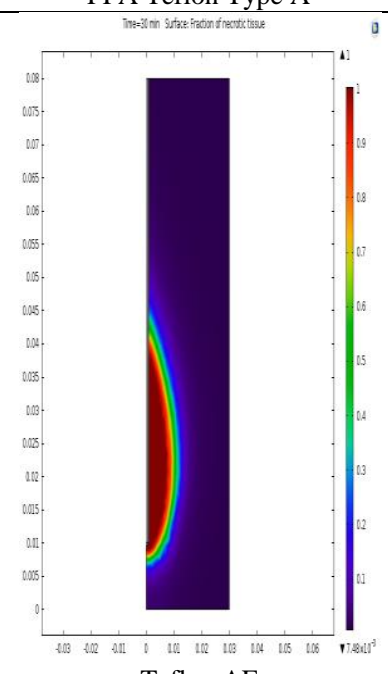

Teflon AF

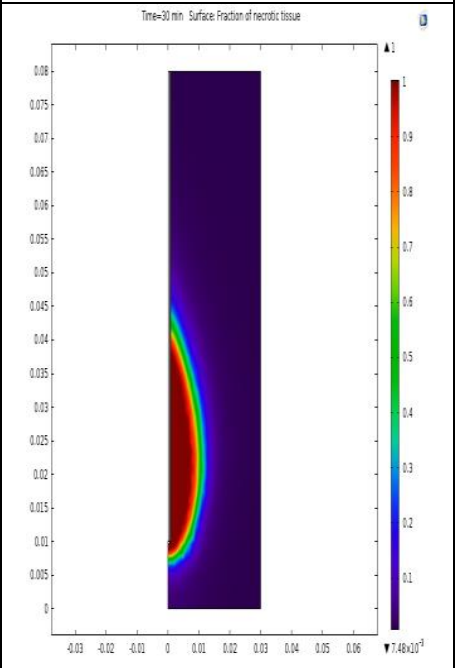

PFA Teflon Type B

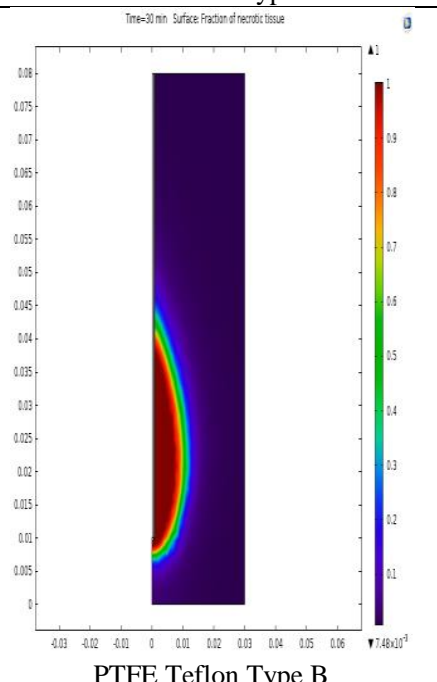

PTFE Teflon Type B

Fig. 2. Necrotic tissue fraction

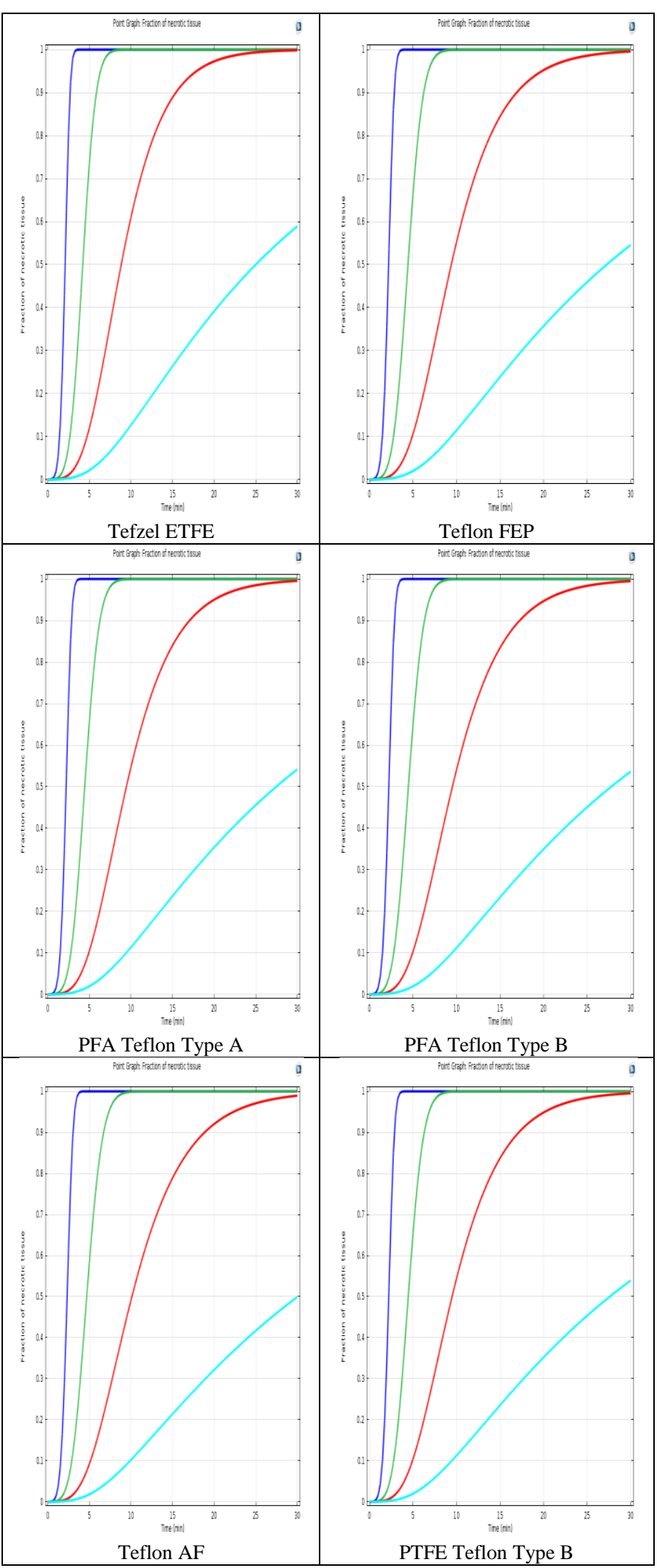

Fig. 3. Tissue necrotic fractions at points $4,6,8$, and $10 \mathrm{~mm}$ 


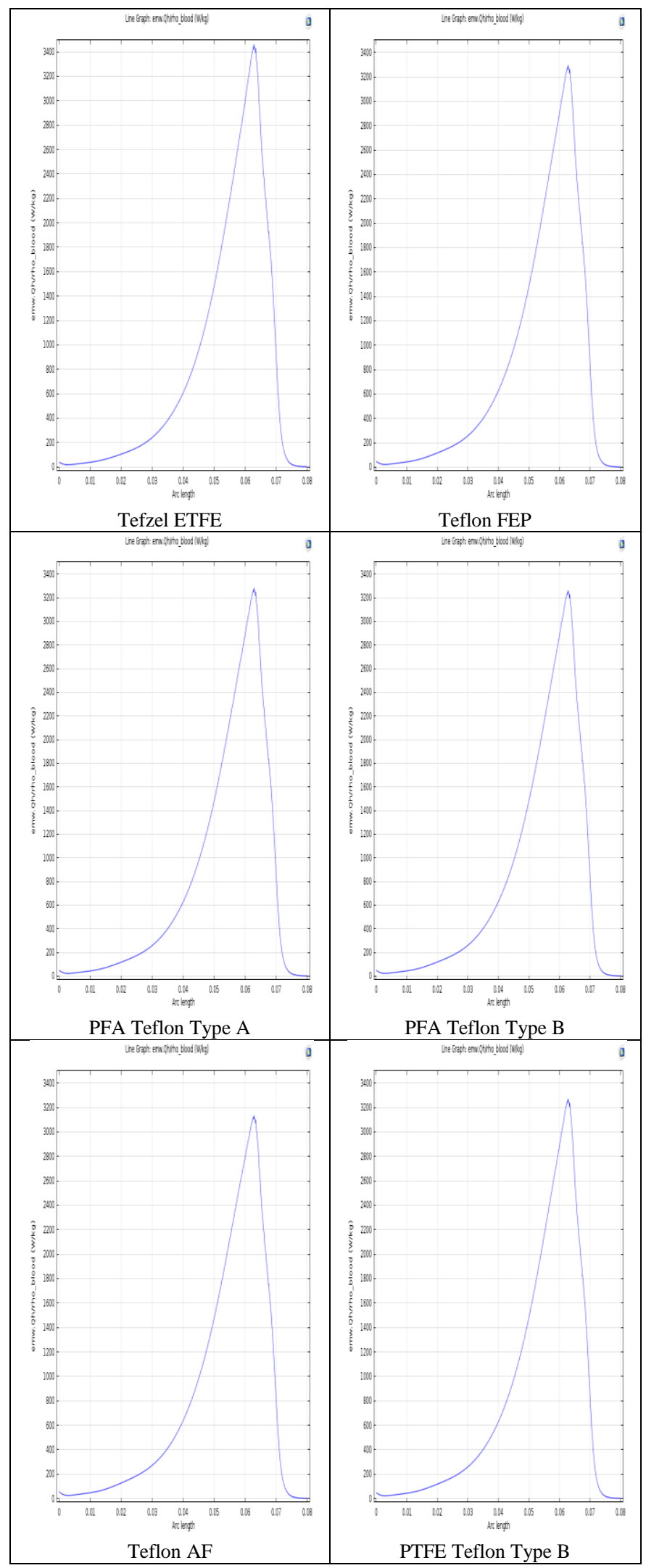

Fig. 4. Specific absorption rate at point $2 \mathrm{~mm}$ from the conductor axis

The rate of absorption of input power by tissue to a great level contributes to the determination of the extent of thermal lesion. The extent of absorption is shown in Table IV for all the catheter materials used in this study. The Tefzel ETFE catheter just as for the other considered parameters absolved the most of the input power, and the rate of this absorption was found to be proportional to the relative permittivity of the catheter materials with Teflon AF having the least absorption.

TABLE IV: INPUT POWER ABSORPTION RATE

\begin{tabular}{ll}
\hline \hline Catheter Material & $\begin{array}{l}\text { Tissue } \\
(\mathrm{W})\end{array}$ \\
\hline Tefzel ETFE & 9.5555 \\
Teflon FEP & 9.4762 \\
PFA Teflon type A & 9.4678 \\
PFA Teflon type B & 9.4555 \\
Teflon AF & 9.3609 \\
PTFE Teflon type B & 9.4620 \\
\hline \hline
\end{tabular}

\section{CONCLUSION}

The use of Tefzel ETFE as the catheter material has resulted in the best performance of the therapy despite the fact of subjecting all the studies to the same conditions. This is attributable to his superior relative permittivity values of all the materials tested giving an attestation to the dependence of the extent of thermal lesion achieved which is a function of the tissue temperature on relative permittivity of the catheter material.

\section{REFERENCES}

[1] http:en.m.wikipedia.org/wiki/Human_body_temperature

[2] A. Bettaeib, \& D. A. Averill-Bates. "Thermotolerance Induced at a Mild Temperature $40^{\circ} \mathrm{C}$ Alleviates Heat Shock-Induced ER Stress and Apoptosis in HeLa Cells." Biochimica et Biophysica Acta, vol. 1853, 52-62, 2015

[3] F. H. Cornelis, C. Marcelin, \& J. C. Bernhard. "Microwave Ablation of Renal Tumors: A Narrative Review of Technical Considerations and Clinical Results." Diagnostics and Interventional Imaging, vol. 98, 287-297, 2017

[4] E. R. Cosman Jr. \& E. R. Cosman Sr. "Electric and Thermal Field Effects in Tissue around Radiofrequency Electrodes." American Academy of Pain Medicine, vol. 6, 405-424, June, 2005

[5] Hyperthermia: Microwaves as Cancer Treatment retrieved from http://ethw.org/w/index.php?title=Hyperthermia:_Microwaves_as_Ca ncer_Treatment\&oldid $=154732$, on 20/07/2018

[6] S. P. Psutka, A. S. Feldman, W. S. McDougal, F. J. McGovern, P. Mueller, \& D. A. Gervais. "Long-term Oncologic Outcomes after Radiofrequency Ablation for T1 Renal Cell Carcinoma." Eur Urol, vol. 63, 486-492, 2013

[7] O. Seror. "Ablative Therapies: Advantages and Disadvantages of Radiofrequency, Cryotherapy, Microwave and Electroporation Methods, or How to Choose the Right Method for an Individual Patient?" Diagnostics and Interventional Imaging, vol. 96, 617-624, 2015.

[8] J. Yu, P. Liang, X. Yu, F. Liu, L. Chen, \& Y. Wang. "A Comparison of Microwave Ablation and Bipolar Radiofrequency Ablation both with an Internally Cooled Probe: Results in Ex Vivo and In Vivo Porcine Livers" European Journal of Radiology, vol. 79, 124-130, January, 2011.

[9] J. M. Bertram, D. Yang, M. C. Converse, J. G. Webster \& D. M. Mahvi. "Antenna Design for Microwave Hepatic Ablation Using Axisymmetric Electromagnetic Model." BioMedical Engineering Online, vol. 5(15), 1-9, 2006.

[10] L. J. Higgins \& K. Hong. "Renal Ablation Techniques: State of the Art."AJR,, vol. 205, 735-741, 2015.

[11] F. Cornelis, P. Balageas, Y. Le Bras, G. Rigou, J. -R. Boutault M. Bouzgarrou, \& N. Grenier. "Radiologically-guided Thermal Ablation of Renal Tumors.” Diagnostics and Interventional Imaging, vol. 93, 246-261, 2012

[12] G. Deshazer, P. Prakash, D. Merck, \& D. Haemmerich "Experimental Measurement of Microwave Ablation Heating and Comparison to Computer Simulations." Int J Hyperthermia, vol. 33, 74-82, January, 2017.

[13] A. Z. Ibitoye, T. Orotoye, E. O. Nwoye \& M. A. Aweda. "Analysis of Efficiency of Different Antennas for Microwave Ablation Using Simulation and Experimental Methods." Egyptian Journal of Basic and Applied Sciences, vol. 5, 24-30, 2018. 
[14] T. J. Vogl, N. N. N. Naguib, T. Lehnert, \&N. A. Nour-Eldin. "Radiofrequency, Microwave and Laser Ablation of Pulmonary Neoplasms: Clinical Studies and Technical Considerations - Review Article" European Journal of Radiology, vol. 77, 346-357, 2011

[15] C. L. Brace. "Microwave Tissue Ablation: Biophysics, Technology and Applications" Crit RevBiomed Eng., vol. 38(1), 65-78, 2010.

[16] H. Gao, S. Wu, X. Wang, R. Hu, Z. Zhou, \& X. Sun. "Temperature Simulation of Microwave Ablation Based on Improved Specific Absorption Rate Compared to Phantom Measurements." Computer Assisted Surgery, vol. 22(S1), 9-17, 2017.

[17] C. L. Brace. "Radiofrequency and Microwave Ablation of the Liver, Lung, Kidney and Bone: What are the Differences:" Curr Probl Diagn Radiol., vol. 38(3), 135-143, 2009.

[18] M. Alonzo, A. Bos, S. Bennett, \& H. Ferral. "The Emprint Ablation System with Thermosphere Technology: One of the NewerNextGeneration Microwave Ablation Technologies." Semin Intervent Radiol, vol. 32, 335-338, 2015

[19] G. C. Hui, K. Tuncali, S. Tatli, P. R. Morrison, \& S. G. Siverman "Comparison of Percutaneous and Surgical Approaches to Rena Tumors Ablation." J Vasc Interv Radiol., vol. 19(9), 1311-1320, 2008

[20] S. L. Woldu, G. R. Thoreson Z. Okhunov, R. Ghandour, M. B Rothberg, A. RoyChoudhury, H. H. Kin, M. Bozoghlanian, J. H. Newhouse, M. A. Helmy, K. K. Badana, J. Landman, J. A. Cadeddu, \& J. M. McKieman. "Comparison of Renal Parenchymal Volume Preservation Between Partial Nephrectomy, Croablation, and Radiofrequency Ablation Using 3D Volume Measurements." J Endourol., vol. 29(8), 948-955, 2015

[21] J. A. Long, J. C. Bernhard, C. Pigot, et al. "Partial Nephrectomy versus Ablative Therapy for the Treatment of Renal Tumors in an Imperative Setting." World J Urol, vol. 35, 649-656, August, 2016.

[22] C. Floridi, I. De Bernardi, F. Fontana, et al. "Microwave Ablation of Renal Tumors: State of the Art and Development Trends" Radiol Med, vol. 119, 533-540, July, 2014.
[23] P. Prakash. "Theoretical Modeling for Hepatic Microwave Ablation" The Open Biomedical Engineering Journal, vol. 4, 27-38, 2010.

[24] G. L. DeNardo \& S. J. DeNardo. "Turning the Heat on Cancer" Cancer Biotherapy \& Radiopharmaceuticals, vol. 23(6), 671-679, 2008

[25] A. M. Lerardi, A. Mangano, C. Floridi, G. Dionigi, et al.. "A New System of Microwave Ablation at $2450 \mathrm{MHz}$ : Preliminary Experience." Updates Surg, vol. 67, 39-45, March, 2015

[26] S. C. Campbell, A. C. Novick, A. Belldegrun, M. L. Blute, et al. "Guideline for Management of the Clinical T1 Renal Mass." J Urol, vol. 182, 1271-1279, 2009.

[27] G. Carrafiello, D. Lagana, M. Mangini, F. Fontana, et al. "Microwave Tumors Ablation: Principles, Clinical Applications and Preliminary Experiences." International Journal of Surgery, vol. 6, S65-S69, December, 2008

[28] T. Baere, \& F. Deschamps. "New Tumors Ablation Techniques for Cancer Treatment (Microwave, Electroporation)." Diagnostic and Interventional Imaging, vol. 95, 677-682, 2014

[29] G. Schaller, J. Erb, \& R. Engelbrecht, R. "Field Simulation of Dipole Antennas for Interstitial Microwave Hyperthermia." IEEE Transactions on Microwave Theory and Techniques, vol. 44(6), 887895, 1996.

[30] C. L. Brace, D. W. Van der Weide, F. T. Lee, P. F. Laeseke, \& L. Sampson. "Analysis and Experimental Validation of Triaxial Antenna for Microwave Ablation.” IEEE MTTS Int Microw Symp, vol. 3(6-11), 1437-1440, 2004.

[31] C. L. Brace. "Microwave Ablation Technology: What Every Use Should Know" Curr Probl Daign Radiol. Vol. 38(2), 61-67, September, 2010

[32] COMSOL (2014), "Microwave_cancer_therapy" COMSOL 5.0 (Build: 202). 